\title{
EVOLUTIONARY HISTORY OF APORRHAIDAE (GASTROPODA, MOLLUSCA)
}

ROY, Kaustuv, Department of Geophysical Sciences, University of Chicago, 5734 S. Ellis Avenue, Chicago, IL 60637, U.S.A.

The Aporrhaidae is an important family of marine gastropods whose members are characterized by an expanded apertural lip. A phylogenetic analysis of this clade confirmed its monophyly although a few of the constituent genera, as presently defined, are polyphyletic. Stage-level diversity data for the Northern Hemisphere genera gathered through fieldwork, visits to museum collections and from the literature indicate an initial radiation of this clade during the middle Jurassic. This radiation produced 9 genera by the end of Callovian. Similar levels of generic diversity were maintained throughout latest Jurassic and the earliest Cretaceous. During the Jurassic the aporrhaids appear to have been geographically restricted to Europe and Africa. However, given the paucity of Jurassic marine sediments on most continents, this distribution is probably biased although absences in Japan and North America are probably genuine. The later part of the early Cretaceous history of this group is characterized by a major faunal turnover which resulted in the extinction of over 70\% of the Jurassic genera and the evolution of at least 10 new Cretaceous genera. The group reached its highest diversity during the Albian, followed by a slight decline during the Cenomanian. This diversity peak is at least partially attributable to the exceptional quality of preservation during the Albian which is unsurpassed in any Jurassic or Cretaceous stages except the Maastrichtian. The average diversity for the rest of the Cretaceous stages remained around 12 genera and by late Cretaceous the group achieved a global geographic distribution. The aporrhaids suffered a severe setback during the Maastrichtian when at least $75 \%$ of the genera went extinct. The stratigraphic data presently available does not provide enough resolution to determine whether this extinction coincided precisely with the K-T event. At the generic level this extinction does not seem to exhibit any selectivity based on geographic range. Of the three end-Cretaceous survivors, Drepanocheilus and Arrhoges were widespread geographically while the third, Aporrhais had a restricted distribution. Similarly the taxa that perished included both endemic genera and widespread ones like Quadrinervus. The Cenozoic history of the clade is characterized by very low levels of generic diversity and restricted geographic distribution with only two extant genera.

From a macroevolutionary perspective, the late Neocomian turnover as well as the Maastrichtian extinction of aporrhaid genera are particularly interesting. The first event gave rise to a number of distinctive morphologies and coincided with the radiation of various groups of durophagous predators such as decapod crustaceans as well as with the rise of the carnivorous gastropods. The nature and timing of this change suggests that it could be a part of the broader Cretaceous faunal reorganization commonly known as the "Mesozoic marine revolution" (Vermeij, 1977). The end-Cretaceous event is interesting for its magnitude as well as its consequences. The aporrhaids maintained a remarkably stable generic diversity level from mid Jurassic to late Cretaceous, but never recovered from the Maastrichtian extinction. This pattern is in direct contrast to that exhibited by the sister group of Aporrhaidae, the Strombidae. The strombids exhibit extremely low generic diversity and restricted geographic distribution during the Cretaceous but radiated rapidly during the early Cenozoic. Such reciprocal diversity trends, combined with close phylogenetic relationship and functional similarity of the two groups as well as the presence of morphologic convergence, suggests extinction induced replacement and seems to be consistent with models proposed by , among others, Hallam (1987) and Rosenzweig \& McCord (1991). 